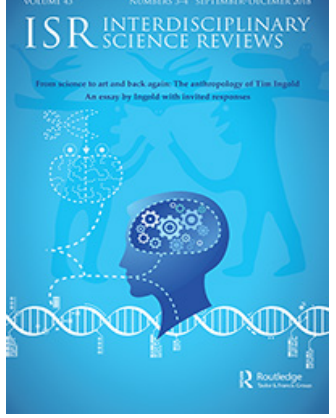

Interdisciplinary Science Reviews

\title{
Ethics and architectural drawings: a framework for discussion
}

\section{Seyit Ermiyagil \& Yonca Hürol}

To cite this article: Seyit Ermiyagil \& Yonca Hürol (2021): Ethics and architectural drawings: a framework for discussion, Interdisciplinary Science Reviews, DOI: 10.1080/03080188.2021.1907930

To link to this article: https://doi.org/10.1080/03080188.2021.1907930

$$
\text { 曲 Published online: } 15 \text { Apr } 2021 .
$$

Submit your article to this journal $\sqsubset$

\section{Q View related articles $₫$}

View Crossmark data $\nearrow$ 


\title{
Ethics and architectural drawings: a framework for discussion
}

\author{
Seyit Ermiyagil (1D ${ }^{\mathrm{a}}$ and Yonca Hürol ${ }^{\mathrm{b}}$ \\ ${ }^{\mathrm{a}}$ Department of Interior Architecture, Eastern Mediterranean University, Famagusta, Turkey; ${ }^{\mathrm{b}}$ Department of \\ Architecture, Eastern Mediterranean University, Famagusta, Turkey
}

\begin{abstract}
The intersection between architecture and ethics has resulted in fruitful debates, but the specific ethical concerns posed by architectural drawings have seldom been explored. This paper presents a quantitative analysis of observations made about architectural drawings that were submitted for a case in North Cyprus and a qualitative analysis of discussions conducted with 15 architects. These observations were made with reference to applied ethical theories and codes of conduct to validate the existence of perceived ethical problems with the drawings. The views expressed by the architects revealed a need for the introduction of new rules and regulations concerning the ethical issues posed by architectural drawings since such issues could, if left unresolved, harm the integrity of the profession.
\end{abstract}

\section{ARTICLE HISTORY}

Received 15 January 2021

Accepted 22 March 2021

\section{KEYWORDS}

Applied ethics; code of ethics and professional conduct; architectural drawings; architectural drawing problems; architectural competition; sales catalogues of construction companies; inconsistency; misleading promise; readability; error

\section{Introduction}

Imagination is an integral part of the design process. Architects use imagination to translate dreams into reality, represented by drawings. Consequently, these drawings are presented to those concerned. Drawings are acts that turn dreams into something tangible. In the exploration of the relationship between drawings and ethics, one needs to bear in mind that any act aims to change or influence behaviour, and in the execution of any act, one needs to think of alternative actions and their consequences, which then need to be appraised in terms of their ethical implications (Lloyd 2009). The fact that architectural drawings, which have always been the means for the acceptance and construction of a project, are now also being used as promotional instruments creates a potential conflict of interests, and may pose ethical problems. Our concern escalated when discrepancies were found between the architectural drawings for the same project, and deviances from the basic drawing standards were observed as well as inconsistencies between these drawings and the intended message of the finished project. This paper initially sought to validate this perceived problem in light of the codes of ethics and conduct, which provide guidelines for the minimum standard of appropriate behaviour in a professional context. Nothing specific was found regarding architectural drawings in the codes of conduct that was scrutinized but there were implications. Therefore, 
references were also made to applied ethics, which is defined as the employment of an ethical theory to make the right decision.

There are many dimensions of applied ethics that can be applied to architecture. Moral standing, which compares animals' standing with humans (Morris 2011), social responsibility (Freeman 2009), environmental ethics (Callicott 1994; Roston 2012), and engineering ethics (Martin and Schinzinger 2005), can be listed. Research in architecture relates moral standing to functional and aesthetic issues (Mould 2016; Karthaus, Block, and $\mathrm{Hu} 2019$ ), the connection between social responsibility and urban issues (Eckenwiler 2018), the link between environmental ethics and climatic issues (Farmer and Guy 2010), and the need to preserve historical environments (Barry 2017). There is also research linking engineering ethics to the technological dimension of architecture (Hürol 2009; Hürol, Yüceer, and Şahali 2014) as well as the economy (Karakhan and Gambatase 2017).

Although no existing research was found on ethics and architectural drawings, applied ethics theories can be employed to address various problems. For instance, Aristotle, the founding father of virtue ethics, argues that every act needs to be logical/reasonable through the use of virtues (Talbot 2011b); Deontology, as expounded by Immanuel Kant (2012), opines that what is required is for an act to be worthy of happiness and that only those who are attuned with the moral law deserve happiness; and according to utilitarianism, an action is considered to be right if it produces the greatest happiness for the greatest number (Talbot 2011e). This paper offers an empirical contribution to this debate by invoking the applied ethics theories of virtue ethics, deontology, and utilitarianism.

The identification of the perceived ethical problems was carried out in a field study that sampled the sale catalogues of 20 different projects of construction companies and of the 281 vertical presentation boards (VPBs) of architectural projects that were entered for competitions held in North Cyprus. The perception held by the researcher that architectural drawings posed ethical issues was given credence by 15 awardwinning participants at a workshop that was organized as the latter part of the field study, which resulted in the identification of the ethical problems of Inconsistency ${ }^{1}$, Misleading Promise ${ }^{2}$, Readability ${ }^{3}$ and Error. ${ }^{4}$ These identifications highlighted the fact that, intentionally or not, contradictory information about projects was being projected by architectural drawings. Due to the high rate of occurrence in both the sale catalogues and the VPBs, the problems of readability and error, both of which were initially thought to be problems of competence, were scrutinized for the purposes of this paper. They were explored in the light of the applied ethics theories and codes of ethics and conduct to secure an understanding of the extent of the ethical problems in architectural drawings in North Cyprus.

Most ethical problems present issues that are not easily solved. Therefore, to establish if and when architectural drawings become ethically problematic, this research sought

\footnotetext{
${ }^{1}$ Inconsistency problem implies discrepancies in the information provided by the drawings and/or what the actual dimensions/attributes of the building would be upon its completion.

${ }^{2}$ Misleading promise implies a promise made by the drawings that may not be attainable.

${ }^{3}$ Readability problem implies the failure of the drawings to accurately explain the architectural project.

${ }^{4}$ Error is the distortion of meaning caused by the drawing itself.
} 
guidance from applied ethics to determine how to manage the ethical problems posed by architectural drawings.

\section{Architectural drawing problems as ethical problems}

To understand how to address the ethical problems believed to be posed by architectural drawings because the message being projected is not 'the truth and nothing but the truth', a close examination of several Codes of Ethics and Conduct ${ }^{5}$ was deemed necessary because such codes are formulated to provide guidelines for the minimum standard of appropriate behaviour in a professional context. The codes that were utilized for this research were those of the Union of Chambers of Turkish Engineers and Architects (UCTEA), Chamber of Architects of Turkey (CAT), Union International des Architect (UIA), the Architect Council of Europe (ACE), the American Institute of Architecture (AIA), and the Royal Institute of British Architects (RIBA). The code of UCTEA-CAT was the first to be scrutinized because this body is the sole overseas architectural organization with which the Chamber of Architects of North Cyprus (UCTCEA-CAT) which does not share the code of conduct of its own has any collaboration with. The code of the UIA was also explored because of the influence it wields in the universal development of architecture. The code of the ACE was among those explored because of its international prestige and because of the aim of the UCTCEA-CAT to establish EU norms and standards for the architectural profession in North Cyprus. The codes of AIA and RIBA were scrutinized because of their immense global influence despite being national professional organizations. AIA globally sets the benchmark for architects for education and professional development, while RIBA is universally regarded and respected in the influence it wields.

This effort focussed on the scrutiny of codes of ethics and conduct aimed at identifying the perceived problems in architectural drawings and to find necessary clues that indicate how to respond to them. This proved to be elusive as no references to drawing problems were found in any of them.

Guidance was then sought from relevant applied ethics theories because they determine what kind of action should be taken in any given case and offer several different approaches. Talbot (2011a) and Fisher (2010), for instance, listed five applied ethics theories: virtue, non-cognitivism, deontology, utilitarianism, and contract. Virtue ethics, deontology, and utilitarianism were employed for this paper. Virtue ethics was chosen because of the prominence it gives to virtuous acts (Talbot 2011b; Fisher n.d.; Velasquez et al. 2015). The ramification of this for the architectural profession is the respect it implicitly demands basic drawing standards. Deontology was another approach that was scrutinized because it emphasizes the duty of professionals to those they serve (Kant 1998; Fisher 2010; Talbot 2011d; Fisher n.d.; Velasquez et al. 2015). According to Fisher (n.d.), for architects, this means a call to exercise independent reasoning to take the correct action. Utilitarianism was also studied because of its plain rationale: the correct deed is the one that amplifies what is good for the maximum number of people (Mill 2001; Talbot 2011e; Fisher n.d.; Velasquez et al. 2015). Non-cognitivism -

${ }^{5}$ Codes of Ethics and Conduct that set and apply rules of conduct in the profession of architecture in accordance with global and local interests and the codes of UCTEA-CAT, UIA, ACE, AIA, and, RIBA were examined. 
which judges whether a deed is good or not by looking at its results (Talbot 2011c) - was not among the applied ethics approaches that were examined for this paper because of the conviction that an ethical deed does not require the endorsement of anyone else (as explained by Kant, cited in Talbot 2011d). As this research was solely concerned with the architectural drawings employed at the presentation of projects, and contract ethics is concerned with every single phase of construction projects, contract ethics was also among those that were not scrutinized.

The selected theories were then mined for indications of what decisions need to be made in any given case. Even though the search for anything that concerned such architectural drawings was a futile effort, there was an underlying assumption that they would still be a source of guidance.

One indication - everything is here for a reason - was found in virtue ethics (Talbot 2011b). Consequently, a good person is a person who fulfils this reason. Aristotle argued that human beings are here to do logical/reasonable things by employing virtues (cited in Talbot 2011b). Further, Fisher (n.d.) explains that these virtues are present in all professional practices and that these virtues can and do help architects at many levels. Moreover, Velasquez et al. (2015) believe that a virtuous person is more prone to stay loyal to moral principles.

Deontology, on the other hand, proffers that one should not opt for wrong acts, regardless of what their outcome may be. According to Kant (1998), it is the moral law that motivates the right action and accordingly, all professionals have a duty to those whom they serve. According to Fisher (n.d.) in the case of architects, this duty is ingrained in their professional authorization, which requires independent judgement to do what is right.

Utilitarianism, which focuses on results in the search for what is right and what is not, contends that every deed must result in the happiness of society (Mill 2001; Talbot 2011e; Fisher n.d.; Velasquez et al. 2015). According to this approach (Talbot 2011e); individuals should concentrate on the greatest happiness principle. In other words, the right action is the one that generates 'the greatest happiness for the greatest number of people'. This theory has a simple logic: whatever action maximizes the greatest amount of good for the greatest number of people is the right course of action (Fisher n.d.).

The ethical principles gleaned from virtue ethics, deontology and utilitarianism indicate that architects should not make any sacrifices in their devotion to the basic drawing standards, which requires competence. Architects have a professional responsibility to ensure that every drawing provides an accurate explanation and that the purpose of every drawing is to serve society by ensuring the happiness of the optimum number of people.

A thorough examination of the codes of conduct to find a specific reference to architectural drawings also proved to be in vain, but it did emphasize the requirement for honesty in the profession. 'No Architect shall either communicate or promote or represent themselves or their professional services in a false or deceptive manner ... ' (ACE 2016; AIA 2017; UCTEA-CAT 2018; UIA 2010); ' ... when engaged in any form ... they should act fairly and honestly... ' (RIBA 2016). The principle that applies to architectural drawings is that honesty must be inviolable.

The drawings that were regarded as problematic were subsequently subjected to additional scrutiny in light of the indications from applied ethics and the codes of 
conduct. This effort reinforced the perception that these drawings posed several ethical concerns. One of the conclusions was that they were not the result of virtuous acts. Virtue ethics puts special emphasis on competence to avoid the communication of incorrect information. These drawings did not meet this requirement. Some of these drawings did not seem to offer a true explanation of the project. Neither did they seem to be occupied with any quest 'to make as many people as possible happy'. Moreover, some did not give the impression that they were honest. On the contrary, they left the impression that they were the works of architects whose competence could be regarded as questionable. What was of notable concern was the prospect that some of these drawings could have been cases of misleading acts. Such acts would be decidedly unrighteous and result in an erosion of societal confidence in the profession.

The motivation for this paper was to validate the perceived ethical problems in architectural drawings in North Cyprus and establish their impact on the profession. It also set out to examine ways in which to respond to the identified concerns. This was realized in the light of the above-explained theories and codes of conduct, which resulted in the identification of the ethical problems of readability and error in architectural drawings.

\section{Establishment of the problem}

Identification and validation of the problems were carried out in a two-phased field study. The first phase, which involved an observational analysis and development of a sample of the perceived problems, concentrated on architectural drawings used in construction company sale catalogues and VPBs that had been submitted to architectural competitions. The second phase was concerned with the validation of the perceived problems through interviews with specialists.

Since the purpose of sale catalogues is to sell a project and the VPBs aim to persuade colleagues of the merits of a project, both can be said to be promotional instruments. However, the different motivations behind them may result in different ethical problems.

Sale catalogues of 20 different award-winning projects of construction companies that operate in the town of Kyrenia ${ }^{6}$ and 281 VPBs of eight award-winning projects that had been entered architectural competitions held in North Cyprus between 2000 and 2018 (a period when technology had revolutionized architectural drawings) were scrutinized. These projects had won awards and had been sold before their completion on the strength of the explanations provided by architectural drawings to juries or customers. Judgements/decisions were based on the assumptions that these drawings were accurate.

This research was qualitative, based on observational analysis, which has considerable similarities with phenomenological observation. During this observational analysis, the drawings were subjected to comparisons made between the established academic standards for architectural drawings and the actual drawings in the catalogues and VPBs.

These comparisons aimed to highlight the problems that were believed to exist in the architectural drawings and to group the ones that displayed similarities to facilitate a debate on the issue.

Due to the concern that sampling of all the identified problems, which totalled 24, would be too complex, one sample representative of each problem type was chosen.

${ }^{6}$ The town of Kyrenia has the highest volume of construction business in North Cyprus. 
Stratified sampling was employed, to ensure that the selections were representative of the sub-headings and that there was an even distribution between groups.

\section{Readability}

A problem arises when $2 \mathrm{D}$ and 3D drawings, which purportedly aim to explain architectural projects, fail to do so. The intention of $2 \mathrm{D}$ and $3 \mathrm{D}$ drawings should be the provision of all possible information about the architectural project in a clear and comprehensible manner.

The scale of the drawings should not hinder the readability of the graphics and textual contexts of the drawings and should not cause any uncertainty. When the $2 \mathrm{D}$ and $3 \mathrm{D}$ drawings are compressed too tightly on the catalogues and/or VPBs, and/or when too many $3 \mathrm{D}$ drawings are used, attention is deflected towards the $3 \mathrm{D}$ drawings, creating an impression that details on the $2 \mathrm{D}$ drawings are not as important. This might hinder an accurate reading of the information. Deviations from the general meaning of the project may result in a problem of readability.

Two main types of readability problems were identified: (F) general sheet organization, and $(\mathrm{G})$ effective/ineffective.

\section{The F-type problem: general sheet organization}

F-type problems arise when 2D and 3D drawings, photographs, diagrams, and texts used in the catalogues and VPBs fail to explain the architectural project because of the way the sheets have been arranged. In the preparation of the catalogues, construction companies tend to use maximum possible $2 \mathrm{D}$ and $3 \mathrm{D}$ drawings, colours, and texts. Therefore, the sizes of the sheets in the catalogues and VPBs or the way that they had been compiled, are of vital importance. Excessive use of drawings and texts on small sheets will hinder their readability.

Eight variants of the F-type problem were identified: sheet dimensions (F1), general drawing scale and sheet size relationship (F2), balance (F3), position (F4), scale (F5), general organization (order) of the sheet (F6), negative and positive area of the sheet (F7), and floating (F8).

The representative sample for the F-type problems was the F6 problem. This was identified through a comparison between the organization of the sheet and the academic standard for 'general organization of the sheet' in architecture courses.

The sample page (Figure 1) is from a sale catalogue. The overlapping and congested layout of the drawings makes it difficult to obtain a clear understanding of the project, and this may obscure certain details.

\section{The G-type problem: effective/ineffective}

G-type problems are created when the 2D and 3D drawings, photographs, diagrams, and texts that explain the architectural project are 'effective' or 'ineffective'. These problems fail to provide the correct information about the project. 'Effective' refers to the use of drawing techniques, computer programs, colours, and perspectives of $3 \mathrm{D}$ drawings that create the intended impressive results that can be used to mislead and obscure the accuracy of the information. 'Ineffective' refers to the use of the above-mentioned techniques without achieving the intended impressive result but also failing to provide 


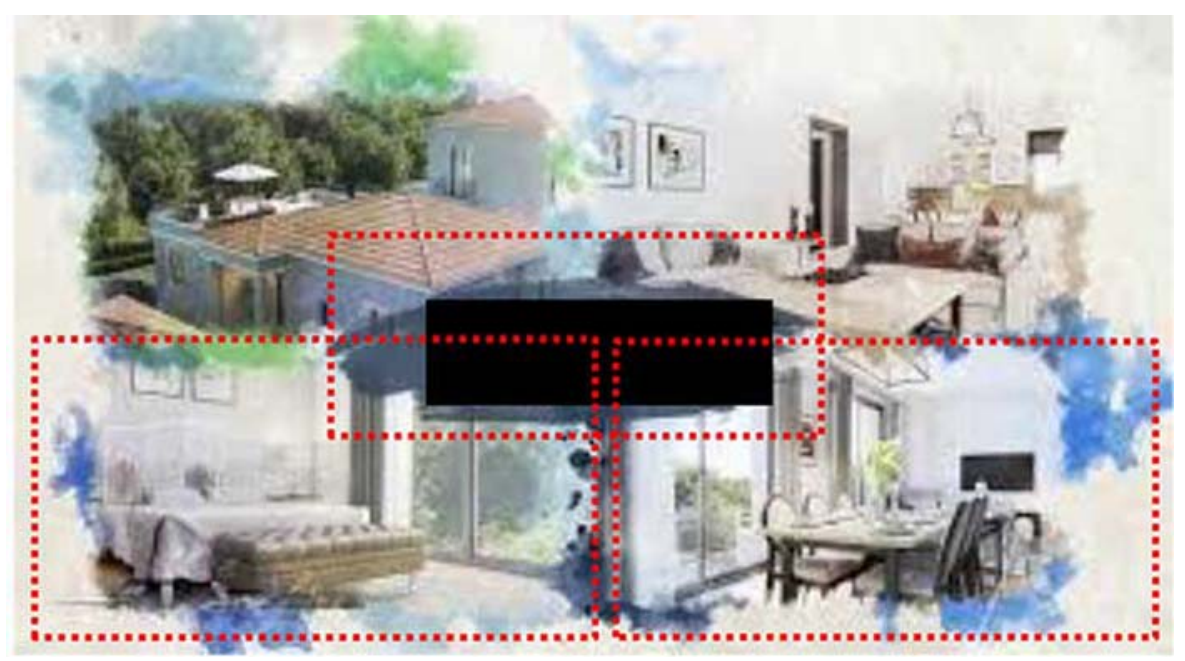

Figure 1. Sample of F6 (http://mehmeteminogluinvestment.com/bella-proje.html, 2018).

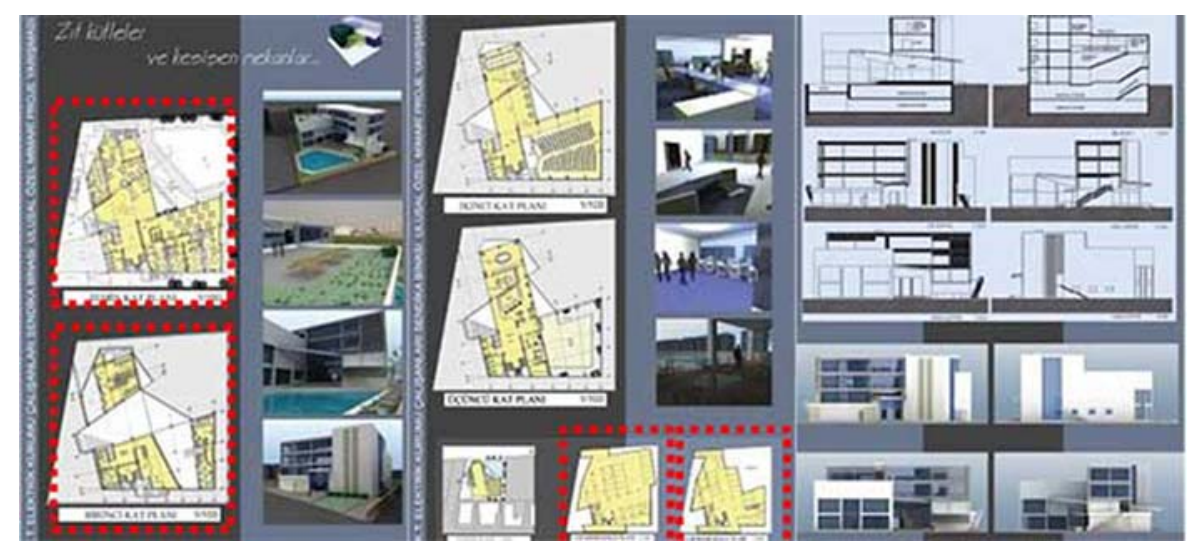

Figure 2. Sample of the G4 (Archive of contestant architects, 2008).

accurate information. They have been grouped under the same problem heading because of the equivalence of their nature despite their contrary names.

Four types of this problem were identified: point of view (G1), unity/uniformity (G2), continuity (G3), and effective/ineffective (G4).

The representative sample for the G-type problems was the G4 problem. The samples below have been cited for cases that involved effective techniques. Similar cases, with opposite effects, can also be considered as samples for ineffective cases. Type G4 was identified through a comparison between the effective drawings on VPBs and the academic standard for 'effective/ineffective' in architecture courses.

Figure 2 depicts how the VPBs were arranged when presented at a competition. They all belonged to the same project. Here, an attempt at effective presentation resulted in an obscuring of the information in the drawings. The use of far too many drawings and colours detracted from the information. Another problem had its origin in the use of 
Table 1. Types of readability problems.

\begin{tabular}{|c|c|c|c|c|}
\hline Problems & Type of problems & Key & Explanation of the problems & Key \\
\hline \multirow[t]{12}{*}{ Readability } & \multirow{8}{*}{$\begin{array}{c}\text { General sheet } \\
\text { organization }\end{array}$} & \multirow[t]{8}{*}{$\mathrm{F}$} & Sheet dimension & F1 \\
\hline & & & General drawing scale, and sheet size relationship & $\mathrm{F} 2$ \\
\hline & & & $\begin{array}{l}\text { Balance of the } 2 \mathrm{D} \mathrm{dwg} / \text { balance of the } 3 \mathrm{D} \mathrm{dwg} / \text { balance of the photos/ } \\
\text { balance of the diagrams/balance of the letters/balance of the north } \\
\text { sign }\end{array}$ & F3 \\
\hline & & & $\begin{array}{l}\text { Position of the } 2 \mathrm{D} \mathrm{dwg} / \text { position of the } 3 \mathrm{D} \mathrm{dwg} / \text { position of the photos/ } \\
\text { position of the diagrams/position of the letters/position of the north } \\
\text { sign }\end{array}$ & F4 \\
\hline & & & $\begin{array}{l}\text { Scale of the } 2 \mathrm{D} \mathrm{dwg} / \mathrm{scale} \text { of the } 3 \mathrm{D} \mathrm{dwg} / \mathrm{scale} \text { of the photo/scale of } \\
\text { the diagrams/scale of the letters/scale of the north sign }\end{array}$ & F5 \\
\hline & & & $\begin{array}{l}\text { General organization (order) of the sheet } \\
\text { - Grid } \\
\text { - Diagonal arrangement } \\
\text { - Congested layout }\end{array}$ & F6 \\
\hline & & & Negative and positive area of the sheet & F7 \\
\hline & & & Floating & F8 \\
\hline & \multirow[t]{4}{*}{ Effective/Ineffective } & \multirow[t]{4}{*}{ G } & Point of view & G1 \\
\hline & & & Unity & G2 \\
\hline & & & Continuity & G3 \\
\hline & & & Efficiency/inefficiency & G4 \\
\hline
\end{tabular}

different scales. The use of different scales for the 2D drawings of any given project not only conceals the details necessary for a proper reading of the project but also hinders the ability to see the relations between the different floor plans. Table 1 provides a synopsis of the readability problems.

\section{Error}

Error is the distortion of the meaning of the drawings caused by aspects of the drawings themselves, such as the clarity of lines, the quality of the drawings, or distorted expressions.

Architectural projects are prepared by professionals, who have the requisite expertize. If the $2 \mathrm{D}$ and $3 \mathrm{D}$ drawings do not meet academic architectural standards and cannot be read, these defects relate to the professional competence of the architect.

Six main groups of error were identified: technical drawing $(\mathrm{H})$, contextual devices (I), detail $(\mathrm{J})$, transparency $(\mathrm{K})$, colour $(\mathrm{L})$, and shade/shadow and texture $(\mathrm{M})$. In each case, the problem was identified through a comparison between the chosen drawings and the established academic standard for that aspect that would be taught in a professional architectural degree course.

\section{The H-type problem: technical drawing}

This problem is concerned with line weight/line quality of the architectural drawings. The failures include: no section lines in the drawings; sections not indicated in a dark colour; hatches that are not to the right scale; hatches of the wrong type.

Two types of $\mathrm{H}$ problems were identified: drawing mistakes (H1), and line quality/line weight $(\mathrm{H} 2)$. The representative sample for the H-type problems was the $\mathrm{H} 2$ type problem.

The sample cited in Figure 3 is a 2D drawing from a sale catalogue. The line quality/ line weight of the drawing of the plan of the ground floor was not in accordance with the 


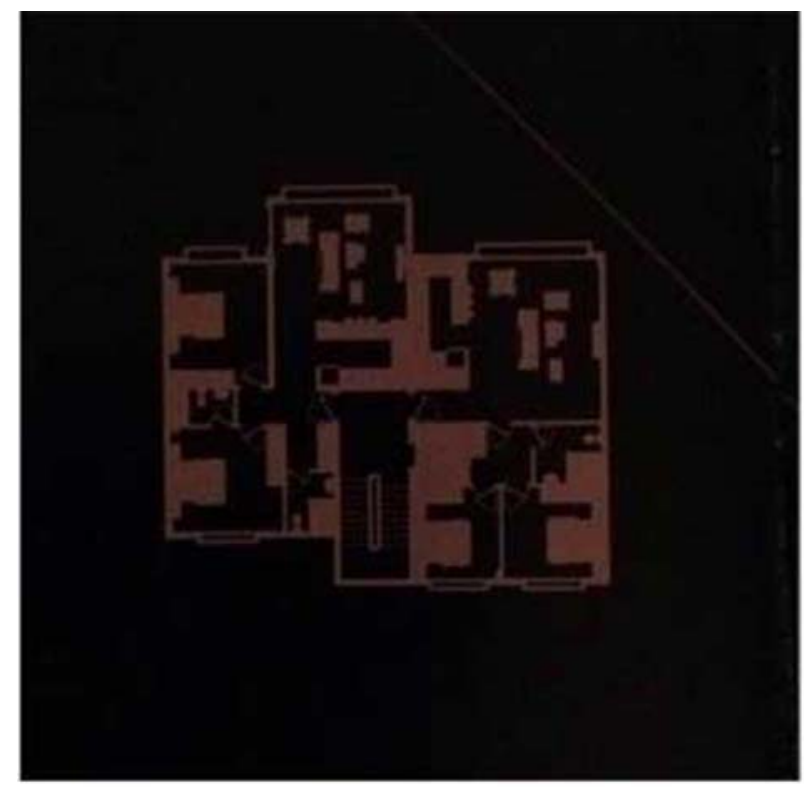

Figure 3. Sample of H2 (E8 sale catalogue, 2016).

basic architectural drawing technique standard. The sole purpose for the use of such plans is to impress the unacquainted.

\section{The l-type problem: contextual devices}

Elements such as surroundings, landscape, and sky are used in architectural project drawings to facilitate a sense of the relationship between the project and its surroundings.

Feeling scale instruments (people/furniture/cars) also enable the user/third parties to assess the scale and functions of the architectural project. However, the choice of certain contextual devices may not relay the correct sense of the scale of the project. They may lend positive or negative meanings to the project, which may not be accurate.

Eight types of problems were identified in this category: surroundings (I1), landscaping (I2), sky (I3), people (I4), furniture (I5), and cars (I6).

The representative sample for the I-type was I1.

The sample (Figure 4) is a $3 \mathrm{D}$ drawing from a sale catalogue. The randomly chosen background of the drawing is not an accurate depiction of the surroundings.

\section{The J-type problem: details}

When the details of the architectural project are not fully solved, 2D and 3D drawings may fail to explain the project in terms of size, material, and finishing details.

Three types of J problems were identified: size, material, and finishing (J1). They were grouped and scrutinized together because of their similarity.

The sample cited in Figure 5 is a 3D drawing from a sale catalogue that does not provide adequate information concerning the materials used for a façade. There is ambiguity about the materials proposed for the façade covering and uncertainty about the product, which will create problems during the realization of the project. Eventually, 


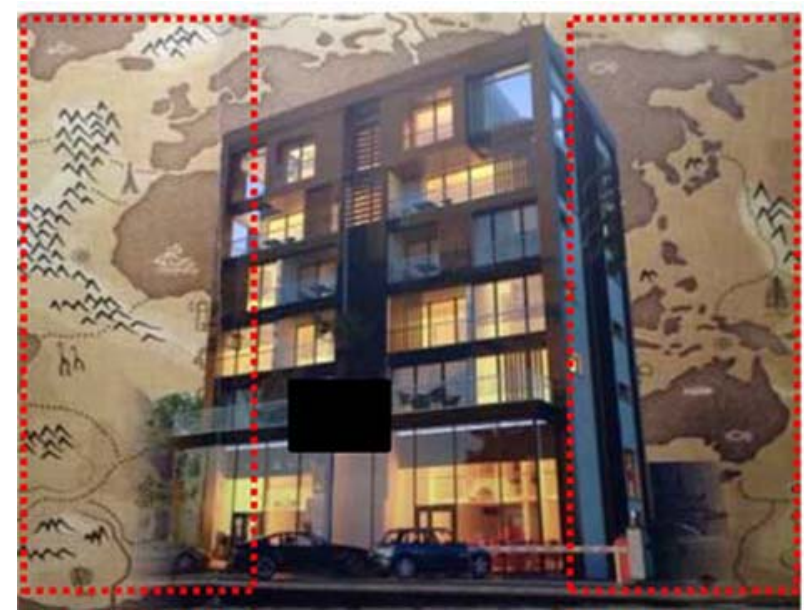

Figure 4. Sample of I1 (E4 sale catalogue, 2017).

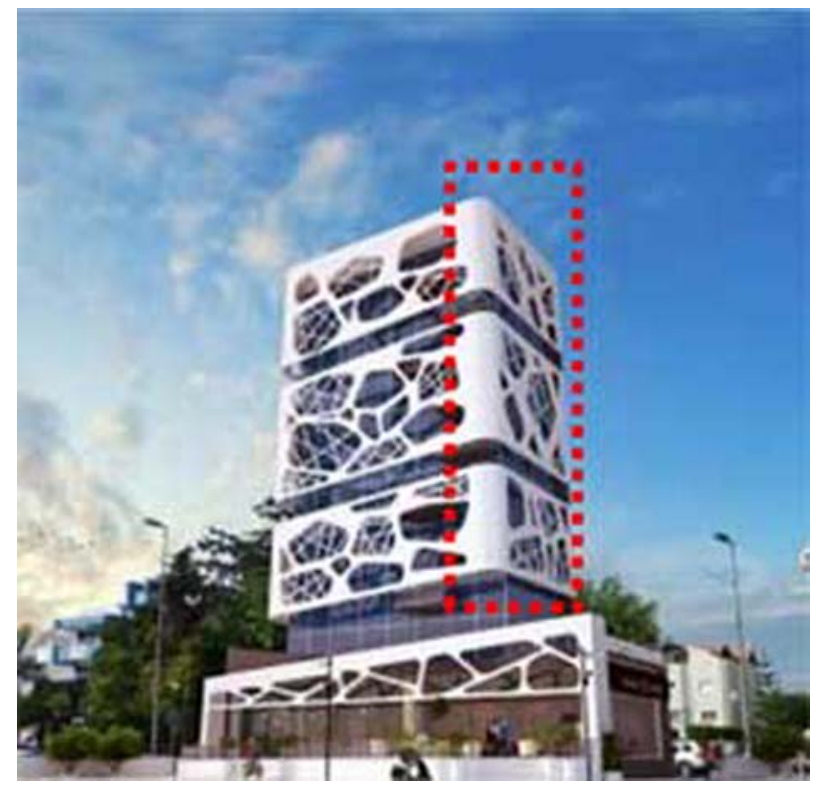

Figure 5. Sample of the J1 (https://www.kibrisemlakmerkezi.com/kibris-konut-projesi/magic-towerprojesi, 2018).

the project was constructed in a different way, which also changed the impression created by the drawing.

\section{The K-type problem: transparency}

These are problems that result from the incorrect use of transparent elements in drawings. For instance, if the surface of a glass used in the drawings is opaque than it should be, a perception is created that the façade of the building is lighter than in it is reality. 


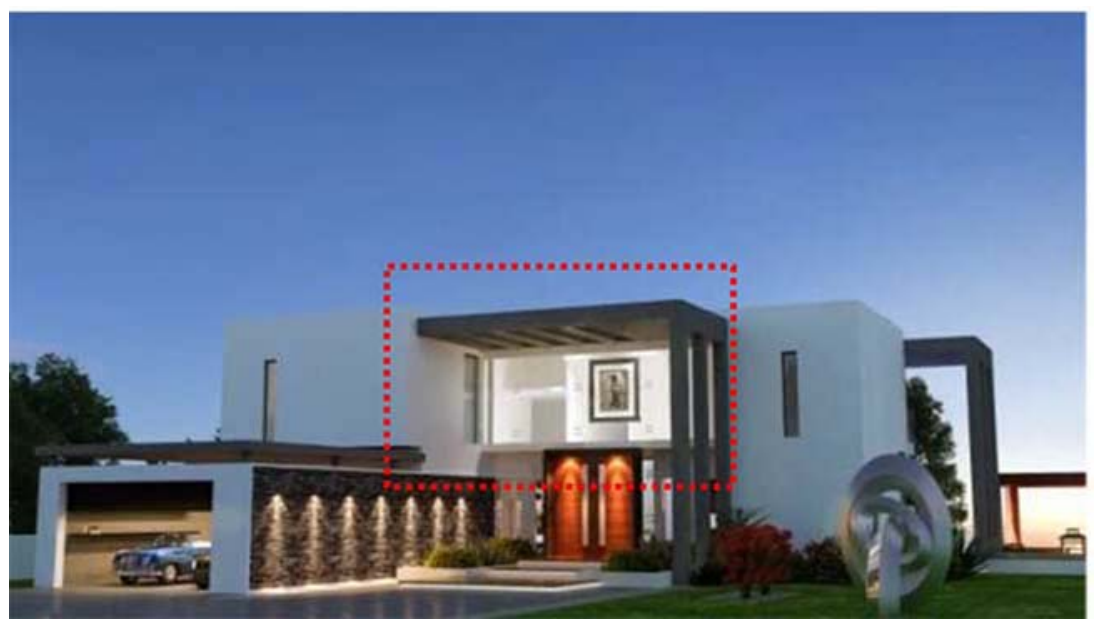

Figure 6. Sample of the K1 (http://mehmeteminogluinvestment.com/bella-proje.html, 2018).

Two types of such problems were identified: opacity and brightness (luminosity) (K1). During the research, they were studied together because of their similarity. The representative sample for K-type problems was the K1 type.

The sample cited in Figure 6 is a 3D drawing from a sale catalogue. The opacity of the glass façade on the first floor has obscured the explanation provided about the project, resulting in uncertainty regarding whether the proposed space is an open terrace or an enclosed area.

\section{The L-type problem: colour}

The use of hue, chroma (saturation), and value will contribute towards the realization of the desired perception of the project. For instance, while the use of warm colours (red, yellow, orange) helps to highlight the importance of architectural elements in architectural drawings, the use of cold colours (blue, green, purple) for details creates the opposite effect. Therefore, knowledge of the psychological effect of colour, which is an important aspect of design, will facilitate the desired perception of the project. The 'colour' problem arises because its incorrect use fails to explain the project.

Three types of this problem were identified: hue, chroma, and value (H1). They were studied together. The representative sample for H-type problems was $\mathrm{H}$.

The sample in Figure 7 is taken from a VPB that was submitted to an architectural competition. The meaning behind the choice of façade colour is not clear. This resulted in uncertainty about the implication of the colour and whether it was used to highlight the architectural elements or materials. This may cause difficulties as the aesthetic target and professional standards of the project may not be realized.

\section{The M-type problem: shade/shadow and texture}

The failure to employ the proper use of shade/shadow and texture in $2 \mathrm{D}$ and $3 \mathrm{D}$ drawings fails to provide a correct explanation of the project. Shade/shadow and texture are used to explain the form of the proposed architectural project, whether it is straight, 

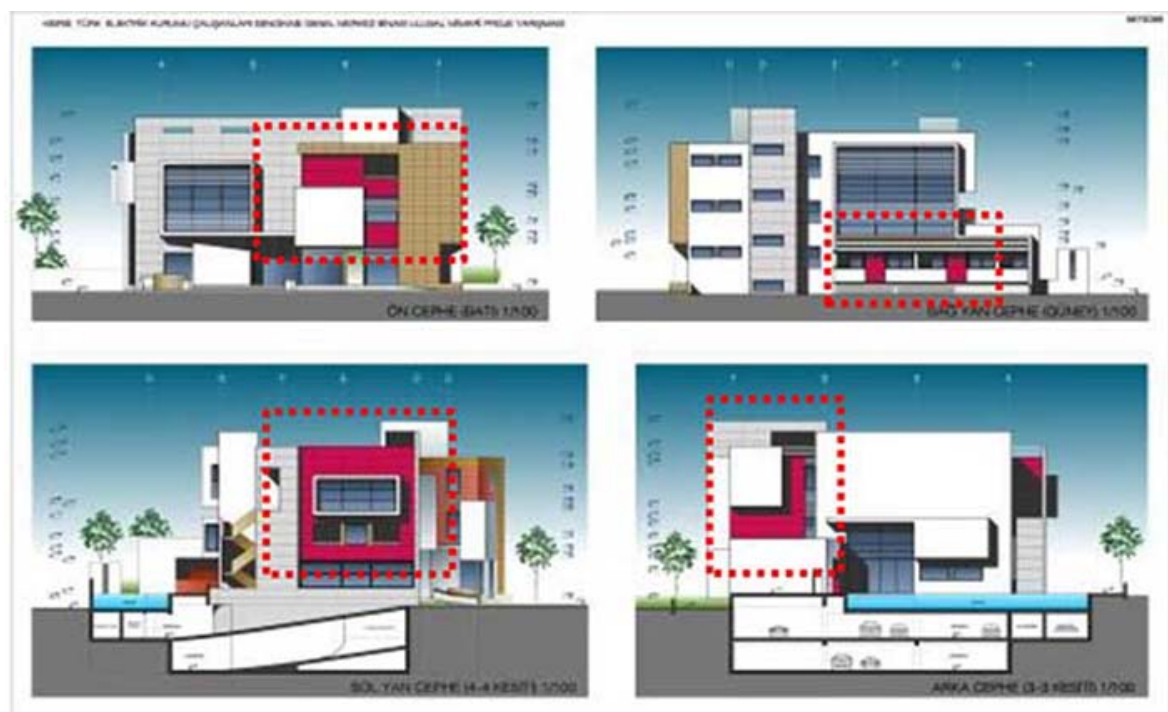

Figure 7. Sample of the H1 (Archive of contestant architects, 2008).

curved, concave, or otherwise. One perceives form and colour through the effects of light and shadow.

Three types of such problems were identified: the sun direction, depth, and form of the surface (M1). They were studied together because of their similarity. The representative sample for M-type problems was M1.

Figure 8 shows a sample of VPBs that were submitted to an architectural competition. There is an explosion of light and colours in these drawings, which obscures the understanding of the form of the surface and its depth. This ambiguity makes the project presentation aesthetically appealing but less accurate. Table 2 provides a synopsis of the main types of problems of error.

The above synopsis, which was the outcome of an observational analysis (Tables 3 and 4) revealed that the problem of readability existed in $100 \%$ of the sale catalogues and $87.5 \%$ of the VBPs. The problem of error was found to exist in $75 \%$ of the sale catalogues and $100 \%$ of the VBPs. The existence of both problems at such high rates is an indication of the need for architects to be more diligent in upholding the drawing standards and a possible warning of a systemic problem in the profession in North Cyprus. This initiated a debate about whether this was an issue concerning competence or the result of a deliberate attempt to mislead, and whether such problems posed ethical issues that had a bearing on the profession.

Conclusions drawn from personal observations and interpretations were based, to some extent, on different values and required verification. Therefore, the second phase of the field study comprised a workshop attended by 15 practising architects (who had succeeded in architectural competitions in North Cyprus). Interviews were conducted to test and verify the existence of the problems of readability and error. The subsequent analysis is based on the qualitative data that was collected during the workshop (Creswell 1997). 


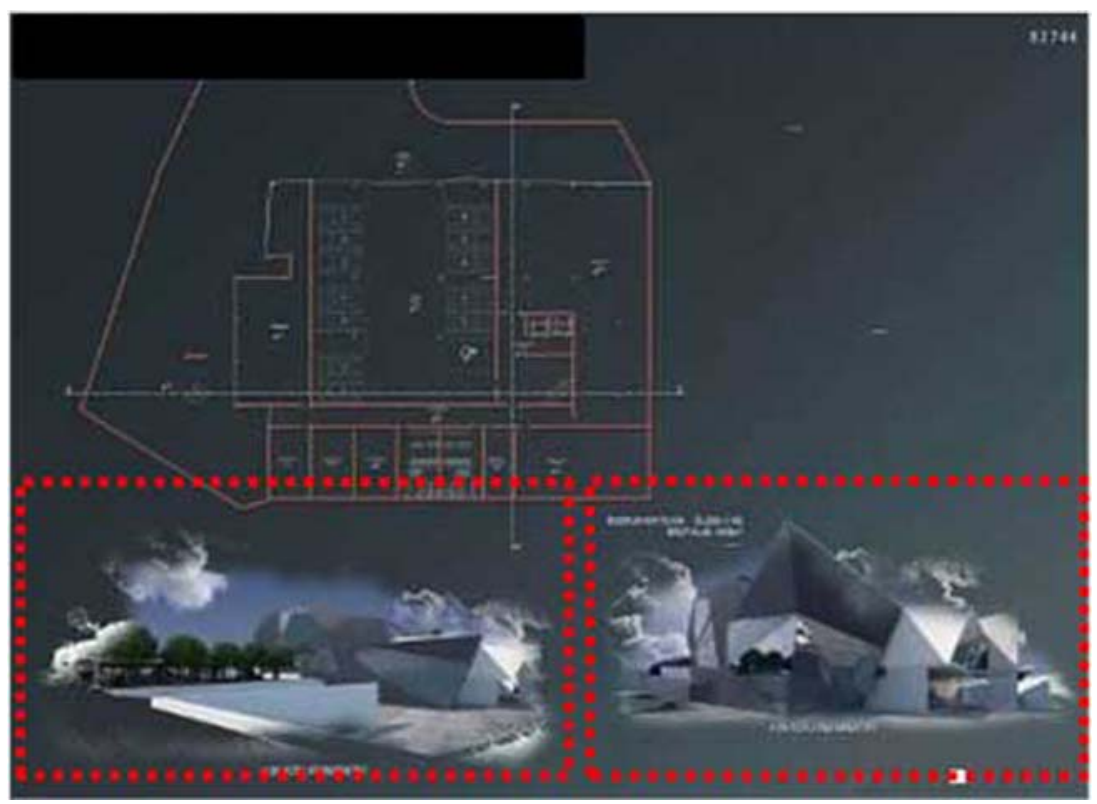

Figure 8. Sample of the M1 (Archive of contestant architects, 2017).

Table 2. Types of error problems.

\begin{tabular}{|c|c|c|c|c|c|}
\hline \multirow{3}{*}{$\frac{\text { Problem }}{\text { Error }}$} & Type of problems & Key & \multicolumn{2}{|c|}{ Explanation of the problems } & \multirow{2}{*}{$\frac{\text { Key }}{\text { H1 }}$} \\
\hline & Technical drawing & H & Drawing mistakes & & \\
\hline & & & Line quality/Line weight & & $\mathrm{H} 2$ \\
\hline & Contextual Devices & I & Environment instrument & $\begin{array}{l}\text { Surrounding } \\
\text { Landscaping }\end{array}$ & $\begin{array}{l}11 \\
12\end{array}$ \\
\hline & & & & & 13 \\
\hline & & & Scale instrument & People & 14 \\
\hline & & & & Furniture & 15 \\
\hline & & & & Car & 16 \\
\hline & Details & J & Size, Material, Finishing & & J1 \\
\hline & Transparency & $\mathbf{K}$ & Opacity, Brightness (Lumir & & K1 \\
\hline & Colour & $\mathbf{L}$ & Hue, Chroma, Value & & L1 \\
\hline & Shade/Shadow and Texture & M & Sun direction, Depth, Forn & the surface & M1 \\
\hline
\end{tabular}

The workshop was designed as a semi-structured interview and the architects, who took part, were all UCTCEA-CAT members. All the participants had entered and won at least two awards at the eight architectural competitions that had been held during the specific period covered by the field study. The participants were the designers of the VPBs that had been scrutinized during the first phase.

The pre-prepared questions were drafted through a superposition of the samples of the perceived problems and, from the guidance that had been provided by the relevant ethical theories and codes of conduct.

Two types of questions were posed to participating architects. The first type (which comprised two questions) sought to validate the existence of readability: (1) 'Does this drawing fail to provide a correct explanation of the project?' and (2) 'Looking at these drawings can one get a clear understanding of the relations between different floors?' Two other questions sought to validate the existence of errors: (3) 'Does this drawing 


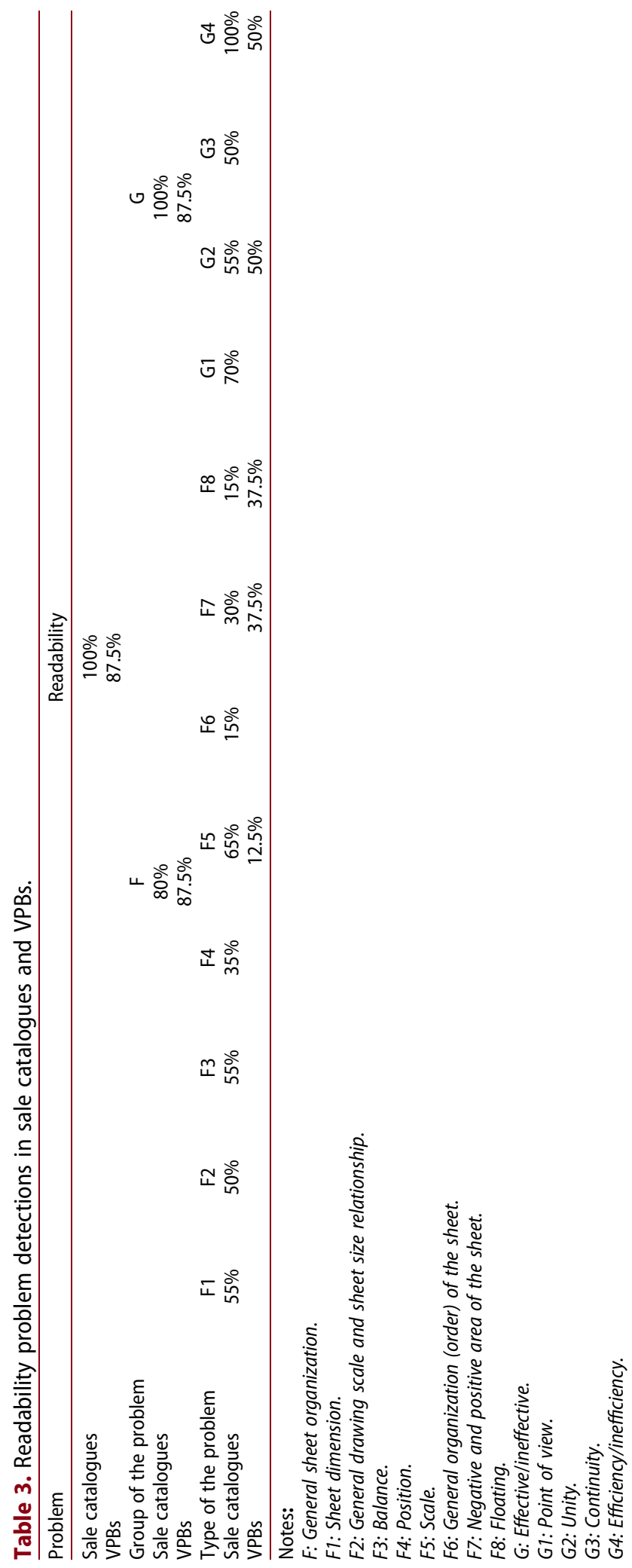


Table 4. Error problem detections in sale catalogues and VPBs.

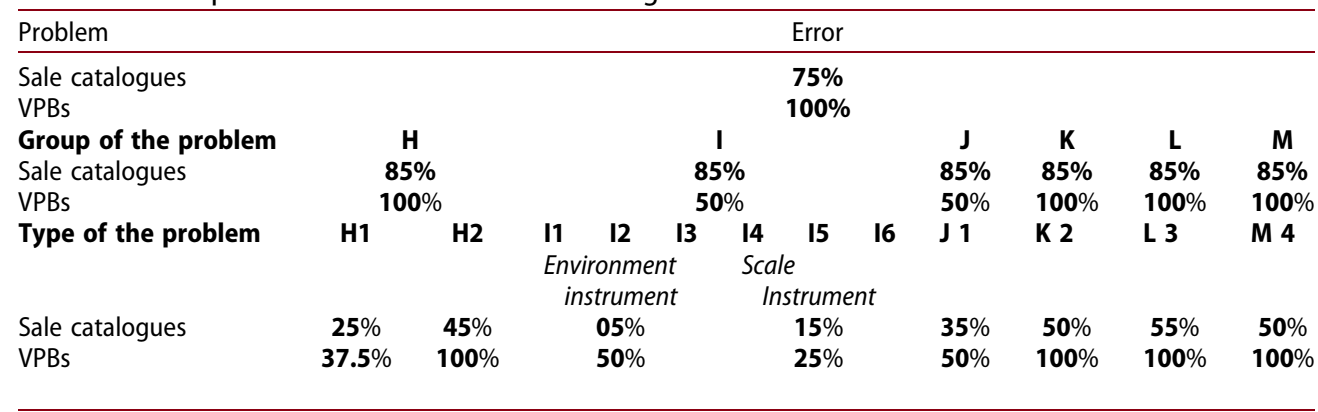

\section{Notes:}

H: Technical drawing.

H1: Drawing mistakes; H2: Line quality/line weight.

I: Contextual devices.

11: Surrounding; 12: Landscaping; 13: Sky; 14: People; 15: Furniture; 16: Car.

J: Details.

J1: Size, material, finishing.

K: Transparency.

K1: Opacity, brightness (luminosity).

L: Colour

L1: Hue, chroma, value.

M: Shade/Shadow and Texture

M1: Sun direction, depth, form of the surface.

fail to provide a correct explanation of the project?' and (4) 'Are these drawings outcomes of competent architecture?' The second type enquired whether the drawings posed ethical problems vis-a-vis applied ethics theories and the codes of professional conduct. All questions had specific aims. Question (5) 'Is this drawing the outcome of competent architecture?' was derived from virtue ethics and sought to generate a debate on competence. Question (6) 'Is it acceptable for all architects to draw like this?' is based on Deontology and sought to ascertain whether these drawings could be regarded as permissible. Question (7) sourced from utilitarianism sought to establish the consequences of the problem for society: 'Can this drawing attitude result in happiness for the majority of the society?' The last question, 'Should architects draw honestly as suggested in the Codes of Ethics and Conduct document of the Chamber of Architects?' was derived from the codes of conduct and sought to verify the need for honesty in architectural drawings.

The workshop was conducted in Turkish and the transcripts of the interviews were examined in four iterations to analyze the original data by differentiating and grouping the similarities observed in the feedback, to capture the general meaning of the feedback and to extricate meaningful phrases in the light of applied ethics theories and codes of conduct.

\section{Ethical problems}

The workshop was constructed to address the ethical problems encountered in the drawings because although these concerns may not have legal repercussions, they are problematic because of their potential negative impact on the profession and society. The first step was to diagnose the problem to secure the best possible understanding. The available 
options could then be gauged by considering the principles of the relevant ethical theories and codes of conduct, by testing the available alternatives, and by reflecting on the possible outcomes.

\section{Readability}

The participants, in their response to the initial question, did not agree with the assumption that a readability problem existed in the drawings. In their opinion, these drawings were readable.

When the workshop moved on to the ethical aspects of drawings by posed by questions sourced from virtue ethics, the discussion focussed on competence. Participant no. 8 voiced the opinion that different drawings can be made under different conditions, and according to different specifications. Yet another argument was that such drawings concerned specifications and conditions, and not competence (Participants no. 8, 9, 16). Another argument was that drawings can be drawn using different scales techniques following specifications and those conditions determine the drawings required (Participants no: 10, 16). The argument concerning specifications was considered acceptable, but the permissibility of drawings varying according to conditions was not. The researcher did not agree, arguing that the sine qua non of any architectural drawing is to provide the best possible explanation of the project to others. These responses implied that an individual does not have to comply with virtue ethics to realize the aim of the profession (Talbot 2011b; Fisher n.d.; Velasquez et al. 2015). Virtue ethics stress that one needs to carry out one's professional obligations to the best of one's capabilities. Under no circumstances, should customer demand, financial aspects, technological inadequacy have a bearing on the principal condition of architectural drawings to provide the best possible, honest explanation of the project. The principles of virtue ethics contradict the argument proposed by the participants that different drawings were permissible under certain conditions.

During the discussion of question (6), which aimed to test the limits for the permissibility of this problem, it emerged that participants disagreed that the samples cited reflected any readability problems. A participant argued that the drawings were clear and encouraged people to dream and thus be happy (Participant no. 5). Two of the participants suggested that they may have been the drawings of other professionals, such as graphic designers (Participants no. 5, 15). However, they did admit that such works could deflect attention away from the essence of the project and that there was a potential threat of disappointment if the illusions created by drawings failed to materialize (Participants no. 5, 9, and 15). Consequently, even though the participants did not think that the drawings had any readability problems, their responses to this question contradicted their earlier assertion that there was no readability problem. Deontology states that wrong acts should not be carried out, regardless of the result (Kant 1998; Fisher 2010; Talbot 2011d; Fisher n.d.; Velasquez et al. 2015). The implication for architecture is that every drawing needs to be accurate. Truth and responsibility are inviolable principles.

During the discussion of the possible consequences of this problem, the researcher stated the opinion that by hiding certain elements of the project, these drawings presented an inflated impression. The participants, on the other hand, believed that these drawings were clear and, therefore, a source of happiness for those concerned 
(Participants no. 5, 18). This, in the opinion of the researcher, was in contradiction with the very essence of drawings whose raison d'etre ought to be the correct explanation of a project and that the whole architectural process should be 'a happiness-inducing experience' without compromising integrity. Happiness with the drawings followed by disappointment as a result of the misunderstandings caused by the drawings is counterproductive. Therefore, the response of the participants to this question conflicted with the ethics of utilitarianism, which also stresses the need for the quality and durability of happiness (Mill 2001).

The discussion of the need for honesty, resulted in unanimous responses . All participants agreed that architects needed to draw honestly as required by the Codes of Ethics and Conduct. One reason given was that nothing should be hidden because these inaccuracies 'would come back to haunt us when the project had been completed' (Participant no. 5). However, the participants also stressed the importance of intention - the hiding of some details did not necessarily signal bad intentions (Participants no. 11, 8 ). This response exposed the fundamental importance attached by the practising professionals to the codes of ethics and conduct for the attainment of honesty and integrity (ACE 2016; AIA 2017; UCTEA-CAT 2008; UIA 2010); the two prerequisites for the profession.

\section{Error}

Initially, all the participants disagreed with the notion that an error problem existed in the drawings. However, as the workshop progressed their responses indicated the contrary.

When the questions derived from applied ethics, virtue theory, and architectural competence were discussed, participants argued that such drawings could harm the realization of the project (Participants no. 9, 16, and 18) and thus be tantamount to a failure in the execution of their jobs. Responses made to the question concerning the error problem revealed an affinity with virtue ethics. According to Aristotle, a virtuous person is one who fills his aim successfully. A virtuous person is the one who does not even consider an unvirtuous act (Talbot 2011b; Fisher n.d.; Velasquez et al. 2015). By stating that they would not draw such drawings because such an act would have a negative impact on the outcome of their work, (Participants no. 9, 16, 18) the architects implied a belief in Aristotle's virtue ethics.

During the discussion of question (6) which aimed to test the limits for the permissibility of the problem, all the participants stressed that every drawing needs to be comprehensible, because unclear drawings would harm the profession (Participant no. 4). The general response to this question revealed that the deontological principle that wrong acts should not be carried out, in any circumstances - was a strong driving force behind decisions made by all participants. What this means for the profession is that drawings should provide the best possible explanation of the project.

During the discussion of the question derived from utilitarianism, one opinion was that drawings with such error problems would not be readable (Participant no. 15). Some argued that such drawings would result in the creation of a feeling of deception among customers (Participants no. 11, 22), while others opined that deceived people do not feel happy (Participants no. 8, 15). In other words, the responses given by the participating architects to this reflected the theory of utilitarianism, which states that a good 
act is an act that creates the most happiness for the most people. The response to this particular question thus displayed the participants' affinity for utilitarianism because they believed that error problems in drawings could cause unhappiness.

The discussion of the need for honesty had a unanimous outcome. All the participants agreed that architects needed to comply with the rules set by the Codes of Ethics and Conduct document. They reasoned that ethical rules had the effect of minimizing the deviations from the project (Participants no. 11,15) by setting a template for behaviour. This has the desired effect of lessening the feeling of deception, imaginary or justified, felt by the customer. This response revealed the importance ascribed to the codes of ethics and conduct by the professionals (ACE 2016; AIA 2017; UCTEA-CAT 2008; UIA 2010).

\section{Conclusion and suggestions}

This research aimed to identify and classify problems in architectural drawings, validate these and apply an ethical framework that could be used to highlight the problems, generate debate, and offer suggestions for actions to be taken to enhance the profession.

During the phase of validation of the perceived problems and discussion of their permissibility, participants did not initially concur with the researcher that the samples under discussion displayed any reading problems, possibly caused by a lack of competence, which could result in ethical problems. They argued that drawings can be made with different scales and techniques, under different conditions. They also rejected the notion that problems would arise if all architects resorted to such drawings. However, by pointing out the dangers inherent in such drawings, they did imply their concurrence with the researcher. The opinion that such drawings would create happiness for the majority also revealed a different conclusion to the one made by the researcher. They did, however, question the longevity of happiness that would be created by such drawings and stressed the need for enduring happiness. There was a unanimous response to the question concerning the Code of Ethics. They agreed that the codes were necessary to protect the integrity of the profession.

There was also a consensus on the issue of the existence of errors in the drawings. They stated that the existence of such problems would harm the realization of the project. Such problems would result in drawings that were not readable, leading to a feeling of deception. They argued that strict adherence to the Codes of Conduct and Ethics would minimize the risk of misunderstanding and ensure greater satisfaction.

At the beginning of the workshop, two main problem headings were consolidated into one, because the participants only concurred on the heading error. The initial opinion held by the researcher that error problems were concerned with competence altered after the responses at the interview which concluded that error problems that misled people were ethical, and not competence issues. What the researcher had perceived as a reading problem was not regarded as such by these architects because they believed that such drawings may encourage people to dream and thus be happy. Another reason why they downplayed any potential significance of such drawings was the belief that they may have been the work of other competent individuals, not architects. However, the researcher thought that the primary obligation of architects in executing drawings is not to make people happy or encourage dreams but to provide the most accurate and comprehensible explanation of the project possible. Drawings should not create 
false expectations. Moreover, even if the drawings were done by non-architect professionals, the architect is still obliged to control them and ensure their accuracy.

The conclusions to be drawn from this study are tentative, but they do define the ethical concerns posed by problematic architectural drawings, their consequences, and the need to find ways to address them. An architect is under obligation to be ethical in the execution of his/her profession. Sub-standard or incorrect drawings imply that architects are failing in their moral and professional obligations. The quality of the drawings, the lingua franca of the profession would be adversely affected if drawings did not offer a correct explanation of the projects. Such an outcome would not only create dissonance in the sector but ultimately reduce public confidence in the profession.

The nature of ethical problems in architectural drawings described in this research is a dispassionate reflection of the architects' views and the findings can be inferred not only as a rallying cry for the need to nurture an awareness of the significance of ethical standards, but also a call for a guideline to make these problems more detectable so that the Chamber of Architects can deal with them within the framework of prescribed rules, if and when any complaints regarding such drawings are lodged.

\section{Disclosure statement}

No potential conflict of interest was reported by the author(s).

\section{Ethical approval}

Approved by the Scientific Research and Publication Ethics Committee of the Eastern Mediterranean University (Ethics approval number: ETK00-2019-0171). See Appendix 1.

\section{Consent to participate}

Informed consent was obtained from all individual participants included in the study. See Appendix 2. Verbal informed consent was obtained before the interview.

\section{Availability of data and material}

The proceedings of the workshop, which lasted two hours, were recorded by two cameras and by four note-takers, whose transcripts totalled 44 A3 type pages. The author will be happy to share them if needed.

Sale catalogues of 20 different projects (totalling 400 pages) and a total of 281 VPBs (jpg or pdf) of eight architectural projects were analyzed with the help of programmes such as Photoshop and AutoCAD. These analyses were compiled in a separate 8 A2 type page booklet. The author will be happy to share them if required.

\section{Notes on contributors}

Seyit Ermiyagil received his Bachelor's Degree in Architecture from the Eastern Mediterranean University Faculty of Architecture in 1999 and his Master's Degree in Architecture from the Architectural Association in London, UK in 2001. His early work experience included acting as Project 
Architect on a variety of housing, commercial, industrial schemes. He has been a senior instructor at the Eastern Mediterranean University since 2016. His major research interests include architectural drawing problems, architectural drawings and ethics.

Yonca Hürol has a PhD in architecture. Since 1998 she has worked in the Department of Architecture at The Eastern Mediterranean University. She became a professor in 2013. Her fields of research include the tectonics of structural systems, tectonics, ethics in architecture and architectural research. She has national and international publications in these subjects. She has also written a book entitled: 'The Tectonics of Structural Systems- An Architectural Approach' which was published by Routledge, Taylor and Francis in 2016.

\section{ORCID}

Seyit Ermiyagil (D) http://orcid.org/0000-0002-5181-9791

\section{References}

The American Institute of Architects (AIA). 2017. Code of Ethics and Professional Conduct. Accessed 24 February 2018. https://cdn.ymaws.com/www.aiaqueensny.org/resource/resmgr/ files/code_of_ethics_2017_.pdf.

Architect Council of Europe (ACE). 2016. European Deontological Code for Providers of Architectural Services. Accessed 13 March 2018. https://www.acecae.eu/fileadmin/New Upload/5._Policies/UPDATED_Policy_2017/Deontological_code_2016.pdf.

Aristotle. 1984. The Complete Works of Aristotle, Volume 2: The Revised Oxford Translation, edited by J. Barnes. New York: Princeton University Press.

Barry, K. M. 2017. "Buildings as Artifacts: Heritage, Patriotism and the Constructed Landscape." Architectural Histories 5 (1): 1-13.

Callicott, J. B. 1994. Earth's Insights. California: University of California Press.

Creswell, J. W. 1997. Creswell Qualitative Inquiry and Research Design: Choosing Among Five Traditions. Sage Publications, Inc. Accessed 25 December 2013. https://b-ok.cc/book/ 1065518/5b9b6f.

D’Anjou, P. 2011. “An Alternative Model for Ethical Decision-Making in Design: A Sartrean Approach.” Design Studies 32 (1): 45-49.

Eckenwiler, L. 2018. "Displacement and Solidarity: An Ethic of Place-Making." Bioethics 32: $562-$ 568.

Farmer, G., and S. Guy. 2010. "Making Morality: Sustainable Architecture and the Pragmatic Imagination." Building Research \& Information: The International Journal of Research, Development and Demonstration 38 (4): 368-378.

Fisher, T. 2010. Ethics for Architects: 50 Dilemmas of Professional Practice. New York: Princeton Architectural Press.

Fisher, T. n.d. "Ethics and Architectural Practice." In: The Profession, Part 1, 13-19. Accessed 25 January 2016. http://media.wiley.com/product_data/excerpt/24/11183088/1118308824-10.pdf.

Freeman, R. E. 2009. "Managing for Stakeholders." In Ethical Theory and Business. 8th ed., edited by T. L. Beauchamp, N. E. Bowie, and D. G. Arnold, 56. New Jersey: Pearson.

Hürol, Y. 2009. "Can Architecture be Barbaric?" Science and Engineering Ethics 15 (2): 233-258.

Hürol, Y., H. Yüceer, and Ö Şahali. 2014. "Building Code Challenging the Ethics Behind Adobe Architecture in North Cyprus." Science and Engineering Ethics 21 (2): 381-399.

International Union of Architects (UIA). 2010. Guidelines for the UIA Accord on Recommended International Standards of Professionalism in Architectural Practice Policy on Ethics and Conduct. Accessed 13 March 2018. https://www.united-architects.org/assets/files/media-files/ UIA\%20Code\%20of\%20Ethics-Accord_0.pdf.

Kant, I. 1998. Grounding for the Metaphysics of Morals. New York: Cambridge University. 
Karakhan, A. A., and J. A. Gambatase. 2017. "Integrating Worker Health and Safety Into Sustainable Design and Construction: Designer and Constructor Perspectives." Journal of Construction Engineering and Management 143 (9): 04017069-1-11.

Karthaus, R., L. Block, and A. Hu. 2019. "Redesigning Prison: The Architecture and Ethics of Rehabilitation." The Journal of Architecture 24 (2): 193-222.

Lloyd, P. 2009 March. "Ethical Imagination and Design." Design Studies 30 (2): 164.

Martin, M. W., and R. Schinzinger. 2005. Ethics in Engineering. 4th ed. New York: McGraw-Hill. Mill, J. S. 2001. Utilitarianism. Kitchener, ON: Batoche Books Limited. Accessed 19 October 2018. https://socialsciences.mcmaster.ca/econ/ugcm/3ll3/mill/utilitarianism.pdf.

Morris, C. W. 2011. "The Idea of Moral Standing." In The Oxford Handbook of Animal Ethics, 701-720. England and Wales: Oxford University Press.

Mould, O. 2016. "Brutalism Redux: Relational Monumentality and the Urban Politics of Brutalist Architecture.” Antipode 49 (3): 701-720.

Roston, H. 2012. A New Environmental Ethics. New York: Routledge.

Royal Institute of British Architects (RIBA). 2016. Code of Ethics and Conduct, Code of Professional Conduct for Members of the Royal Institute of British Architects. Accessed 15 July 2019. https:// www.architecture.com/-/media/gathercontent/code-of-professional-conduct/ additionaldocuments/codeofprofessionalconductpdfpdf.pdf.

Talbot, M. 2011a. “A Romp Through Ethics for Complete Beginners, Session One: Rules, Truths and Theories an Introduction to Ethical Reasoning." Department for Continuing Education, University of Oxford. Accessed 25 January 2016. https://podcasts.ox.ac.uk/rules-truths-andtheories-introduction-ethical-reasoning.

Talbot, M. 2011b. "A Romp Through Ethics for Complete Beginners, Session Three: Virtue Ethics: Virtue Values and Character." Department for Continuing Education University of Oxford. Accessed 25 January 2016. https://podcasts.ox.ac.uk/virtue-ethics-virtue-values-and-character.

Talbot, M. 2011c. "A Romp Through Ethics for Complete Beginners, Session Four: Non Cognitivism Hume, the Passions and Moral." Department for Continuing Education, University of Oxford. Accessed 25 January 2016. https://podcasts.ox.ac.uk/humean-ethicsnon-cognitivism-passions-and-moral-motivation.

Talbot, M. 2011d. "A Romp Through Ethics for Complete Beginners, Session Five: Deontology: Kant.” Department for Continuing Education, University of Oxford. Accessed 25 January 2016. https://podcasts.ox.ac.uk/deontology-kant-duty-and-moral-law.

Talbot, M. 2011e. "A Romp through Ethics for Complete Beginners, Session Six: Utilitarianism: Mill and the Utility Calculus." Department for Continuing Education, University of Oxford. Accessed 25 January 2016. https://podcasts.ox.ac.uk/utilitarianism-mill-and-utility-calculus.

Union of Chambers of Turkish Civil Engineers and Architects (UCTEA)-Chamber of Architects of Turkey (CAT). 2008. Codes in the sphere of Architecture. Accessed 03 March 2020. https://www. tmmob.org.tr/etkinlik/muhendislik-mimarlik-kurultayi-2003/kurultay-kararlari-meslekidavranis-ilkeleri.

Velasquez, M., C. Andre, T. S. J. Shanks, and M. J. Meyer. 2015. “Thinking Ethically.” This article updates several previous pieces from Issues in Ethics. Presentations at the Markkula Center for Applied Ethics. Accessed 25 January 2016. https://www.scu.edu/ethics/ethics-resources/ethicaldecision-making/thinking-ethically/. 


\section{Appendix}

\section{Appendix 1}

\section{Scientific Research and Publication Ethics Committee Approval}

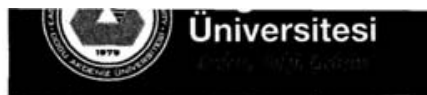

Etik Kurulu / Ethics Committeo

Subject: Application for Ethics.

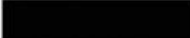

Faculty of Architecture

To Whom It May Concern:

On the date of 08.07.2019, (Meeting number 2019/17-03), EMU's Scientific Research and Publication Ethics Committee (BAYEK) has granted, $\square$ from the, Faculty of Architecture to pursue with his PhD. thesis work "Ethical Problems in Architectural Drawings - The Case of North Cyprus" under the supervision $\square$ This decision has been taken by the majority of votes.

Regards,

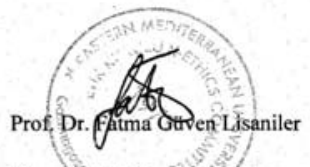

Director of Ethics Committee

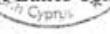

FGL/ns. 


\section{Appendix 2}

\section{A sample consent form}

\section{CONSENT FORM}

\section{Ethical Problems in Architectural Drawings - The Case of North Cyprus - Research Project conducted by PhD student at the Faculty of Architecture, Department of Architecture, Eastern Mediterranean University.}

\section{Research Purpose}

The purpose of the study is to to see whether from a professional perspective the architectural drawing problems were at an acceptable level vis-a-vis the scope of the Applied Ethics theories and Code of Professional Conducts or not.

I understand the information will be used:

1. To inform a PhD thesis at the Faculty of Architecture, Department of Architecture at Eastern Mediterranean University.

2. For possible publication in journals, textbooks or similar publications. In which case I understand that:

- The material may be published in journals world-wide.

- The material may also be placed on a world-wide web site.

- The material may also be used by book publishers.

- The material will not be used for advertising or packaging.

I understand that:

1. Any quotes or views attributed to me will be sent for approval in advance of use in the final report and that consent can be withdrawn at this time.

2. Anonymity will be discussed at the outset of each interview or focus group session. If I request that views expressed by me during the interview or focus group session should appear anonymously, an appropriate form of words will be agreed at or following the interview of focus group session.

Recording of interview or focus group session:

I consent to being recorded (video record / audio record / otter voice notes) during the interview or focus group, as part of the research study. I understand that this information will be used only for the purpose of this study.

PhD candidate:

23.07.2019

Supervisor:

23.07.2019

Name of person taking part in the interview or focus group

Signed:

Date: 23.07 .2019 